\title{
Modeling the interrelationships among environmental forces, organizational capabilities and supply chain sustainability
}

\author{
Mohammad A.K Alsmairat ${ }^{\mathrm{a}^{*}}$ and Abdullah M. Aldakhil ${ }^{\mathrm{b}}$
}

${ }^{a}$ Assistant professor, Luminus Technical University College, Jordan

${ }^{b}$ Associate professor, Management department, College of business, King Saud University, Saudi Arabia

A B S T R A C T

\begin{tabular}{l} 
Article history: \\
Received June 18, 2021 \\
Received in revised format July \\
20,2021 \\
Accepted October 52021 \\
Available online \\
October 52021 \\
\hline Keywords: \\
Environmental forces \\
Organizational capabilities \\
Supplier relationship \\
Sustainability
\end{tabular}

This research aimed to investigate the interrelationships among environmental forces, organizational capabilities, and supply chain sustainability. The mediation role of organizational capabilities and supplier relationship between environmental forces and Supply chain Sustainability were analyzed. Dataset obtained from 410 managers in the Jordanian food industry were used. PLS-SEM was conducted for analysis purposes. The findings reveal that environmental forces and organizational capabilities directly impact supply chain sustainability. The findings have additionally shown that supplier relationships and organizational capabilities played a mediation role between environmental forces and supply chain sustainability. The results show that companies might derive significant benefits from sustainable practices and consider them to maximize the success level of the supply chain sustainability initiative.

\section{Introduction}

The adoption of innovation and technology with a high level of globalization, the more awareness of environmental issues, and the global intention towards protecting the environment and achieving efficient usage of the current resources have brought many challenges and obstacles for all companies around the world (Elrehail, 2018; Alzghoul, 2017). One of the most critical issues is sustainability, which is on the rise due to the harmful influences of organizational practices on the environment (Dzhengiz \& Niesten, 2020; Plambeck, 2009; Afum et al., 2021). The environmental concern and availability of organizational capabilities are seen as critical drivers for achieving sustained competitive advantage (Gong et al., 2020, Giantari \& Sukaatmadja, 2021). By providing complementary capabilities, making environmental relationships, following global environmental regulations, implementing green and sustainable practices, firms can gain innumerable benefits, including reducing costs (Kneipp et al., 2019; Ekins \& Zenghelis, 2021; Mert et al., 2021) in addition to improving product and organization performance (Alhawamdeh \& Alsmairat, 2019; Alzghoul et al., 2018). Pulles et al. (2016) showed that a major assumption of the extended resource-based concept is that enterprises can tap into the resources of others, particularly suppliers, to gain a competitive advantage. In this regard, maintaining and developing strategic partnerships with suppliers can generate an opportunity to benefit from valuable resources of suppliers, which, in turn, reflect positively on sustainable performance and the supply chain network. However, previous literature has also shown that strategic collaborations are more difficult to manage than transactional interactions, as strategic collaborations necessitate larger investments and risk (Prajogo et al., 2021; Min et al., 2005). In today's business world, organizations are not only required to address all these intentions or concerns but also take in their consideration all these issues when they draw and formulate their strategic direction to gain and sustain a competitive market position (Borland et al., 2016; Bae, 2017) and to accomplish their goals and mission efficiently and successfully. Regarding sustainability in the supply chain, researchers have proposed and

* Corresponding author

E-mail address: moh cis2004@yahoo.com (M. A.K Alsmairat)

(C) 2022 Growing Science Ltd. All rights reserved.

doi: $10.5267 /$ j.uscm.2021.10.004 
investigated several drivers that might influence its success. One influence that we address in this paper is environmental forces that replicate the patterns of interrelation amongst internal and external components to cultivate favorable attitudes that allow productive partnership (Sambasivan et al., 2011). Specifically, environmental forces refer to all drivers and pressures that may arise at any phase inside operations in the external environment, such as government laws, labor unions, pressure groups, and local and international environmental organizations. These might result in an organization's inability to recognize, estimate, and understand the potential impact of the environment on the level of changes and how an organization's response to such pressures might be successful or not (Shou et al., 2020; Ahmed et al., 2020). In other words, the positive effects of environmental forces and the uncertainty of avoidance situations by partners within the supply chain depend on the collaboration level between them. The responsibility of achieving sustainable organizational and supply chain performance requires a cooperative effort between all organizational stakeholders in addition to the support from internal organizational capability (Aljuraid \& Alsmairat, 2021; Bae, 2017). Meanwhile, the world is suffering from increasing the strong intention and awareness to sustainability issues, especially in the Coronavirus situation and its impact on the hall societies, a company's responsibility has to be focused on increasing their consideration for internal capabilities and environmental drivers while producing and transferring their different goods and services to the market. The probability of success for organizations to address and align their capabilities, environmental drivers (e.g., government, competitors, legal issues, transportation policy), and what is happening around them is high.

Despite extensive study examining supply chain sustainability, no research has precisely investigated contingencies and boundary conditions that environmental forces and supplier relationships impose on implementing sustainable processes within the supply chain. Numerous studies have investigated such relationships from different perspectives. For example, (Karmaker et al., 2021) pointed out that government support and relationships with the supply chain parties are required to achieve sustainability. Saeed and Kersten (2019) have explored some outdoor drivers such as different types of pressure that are related to market, community, and government and inside drivers that are related to plans, culture, and different organizational structures.

In the context of industrial firms, Graham, (2020) figured out that the supplier's relationship development and the organization's quality capabilities significantly influence the improvement of the manufacturing process, which eventually leads to gaining supply chain sustainability. None of this study considers any factors that can impact (mediate) the consequences of this relation. This investigation tries to fill this gap by analyzing how environmental forces (e.g., government laws, labor unions, pressure groups) can impact supply chain sustainability. Additionally, the mediating role of organizational capabilities (e.g., labor skills, equipment, management style, financial resources) and supply chain relationship will also be analyzed. This paper is conducted to respond to the many scholars (e.g., Ahmed et al., 2020; Dzhengiz \& Niesten, 2020) concerning the interrelationships among organizational capabilities, environmental forces, and supply chain sustainability.

\section{Theoretical foundations and hypotheses development}

Organizations should start by giving more attention to environmental issues and care about environmental forces that greatly pressure organizational success. Subsequently, allowing the accomplishment of profit and benefit from sustainable performance (Paillé et al., 2014). Furthermore, the research conducted by Hervani et al. (2005) has figured out that the sustainability practices adoption helps an organization adjust their supply chain network. This is achieved by optimizing available capabilities, reducing waste, benefiting from the recycling process, and reducing the manufacturing cycle by using the available resources efficiently and effectively (Stonebrake \& Liao, 2006). Accordingly, supply chain sustainability in the organization can carry many benefits, such as maximize the level of the ROI (return on investment) accomplished by a business's globally friendly manufacturing operations and reaching customer's satisfaction and kindness with this type of civilizational practice, which retains the general health of the community and environment. Emmett and Sood (2010) pointed out that organizations can achieve more supplier management, increase the supply chain transparency, and enhance the quality of control in production, which can amend sustainability. Some scholars (e.g.: Berry \& Rondinelli, 1998) have claimed that a practical environmental management preparation is fruitful in lessening hazardous waste. In justifying this concern, the matter of executing suitability must be seen as a planned long-term investment.

The straight benefits, consequently, are hard to be gained. Hence, in late decades, scholars have explored the implication of environmental performance and its involvement in total organizational performance (Rothenberg et al., 2001; Russo \& Harrison, 2005). In their effort to do so, businesses have become worried about justifiable operation performance in different ways, including quality control, the recycling process, reduction waste, 3 pl providers, customer aggregations, and logistics networks.

Many recent scholars have debated supply chain sustainability and have discussed related factors in the organization's context. Lee and Klassen (2008) mentioned and explained three main factors that influence sustainability practices, including customer relationships, suppliers' relationships, and government pressure. Nevertheless, Sarkis et al. (2010) investigated more variables to be included technological, proximal, cultural, organizational, temporal, political, informational, economic, and legal. Lately, Huang (2015) addressed many inclusive factors related to pressures, organizational capabilities, and community awareness. Organizations are affected by different environmental components, either internal or external, and their pressures. However, environmental forces refer to all drivers that initiate and lead firms to adopt any changes or 
implement any new orientation (Köksal et al., 2017). Several past scholars (Saeed \& Kersten, 2019; Hsu et al., 2013; Varsei et al., 2014) have investigated many environmental forces (government, labor unions, suppliers, competitors, regulations, stakeholders) that significantly impact on implementing sustainable practices. These drivers and others influence sustainability differently. For example, the legal environment might influence manufacturing and logistics, while labor unions have more influence on organizational policy and culture. The understanding of different environmental forces not only enhances the firm's reputation and social responsibility but also helps them to gain a new set of capabilities, which in turn reflect on sustaining the level of competition (Saeed et al., 2017).

In sum, we consider that when top management within the organization understands and perceives that its environmental forces have a great strategic value, it is further expected that it will pursue to plan and work accordingly. This argument is agreed with the research conducted by Schrettle et al. (2014), who assume that firms should pursue to analyze the environmental forces, identify priorities, build, and commit to collaboration with partners from which they can benefit the most. However, hypothesis 1 is generated:

\section{$\mathbf{H}_{1}$ : Environmental Forces have a significant direct impact on Supply chain Sustainability.}

Organizational capabilities are the internal environment components in which it operates. Managing and enhancing organizational capabilities are critical to success (Veliyath \& Fitzgerald, 2000; Khaddam et al., 2021). A recent study conducted by (Raman et al., 2006) pointed out that organizational abilities, like IT infrastructure and strategic plan, are playing significant roles in achieving more sustainability and better organizational relationships. Prior research clarifies that organizational capabilities are dispersed to supply chain partners, followed by high performance (e.g., Moneva and Ortas, 2010; Menguc et al., 2010). Accordingly, they may avoid critical challenges and difficulties. Saeed and Kersten (2019) argue that the most significant part in achieving sustainability is the obtainability of organizational resources and capabilities. Similarly, Giunipero et al. (2012) found that the organization's management should allocate sufficient resources, equipment, policy, instructions, and strategies to drive the organization's sustainability activities and initiatives. Ahmed et al. (2020) argue for more research about how competencies and capabilities for companies translate to enhancement tools for environmental drivers and ultimately, the creation of a sustainably responsible supply chain. Additionally, Sanders and Premus (2005) figured out that internal firms' capabilities, such as IT, strategic orientation, employee qualifications, and infrastructure, influence supply chain practices. Scholars have revealed, however, that companies may increase their competitive level through understanding the environmental pressures and their impact and allocate proper capabilities to face these forces and benefit from their supply chain network resources endowments (Karmaker et al., 2021). While environmental forces help organizations create an innovative strategy and wide vision to realize sustainability, it is the organization's capabilities between them that will control and develop the quality of output and allow them to achieve more intended success. Consequently, the following hypothesis is generated:

\section{H2: Organization capabilities have a significant direct impact on Supply chain Sustainability.}

\section{$\mathbf{H}_{3}$ : Organization capabilities mediate the relationship between environmental forces and Supply chain Sustainability.}

Suppliers are crucial at each phase of production, from acquiring raw materials to assisting with production increase and obtaining different resources to enhance output quality (Narasimhan et al., 2006). Prajogo et al. (2021) pointed out that suppliers are the key drivers for companies that provide them the required and updated resources to differentiate their product features and manage their product portfolio. Specifically, supplier relationships refer to cooperative and close relationships between two parties (e.g., organization and suppliers) and plan, work, develop and perform supply chain processes to achieve the set goals, thus accomplishing more benefits than acting independently (Han et al., 2018). Kembi (2021) argues that the organization's relationship with its suppliers supports them in responding to environmental changes and customer demand fluctuations, enhancing its profitability, achieving competitive advantage, and sustaining its supply chain network. However, Wegdam (2021) and Daugherty (2011) suggest that building and maintaining suppliers' relationships might provide more opportunities for organizations to be agile with environmental forces and changes more than they would achieve individually.

Further, many scholars explore the major dimension of the relationships with suppliers, which include commitment, adaptability, communication, dependence, power, and performance (Ambrose et al., 2010). Similarly, Kamau (2013) pointed out that collaboration, commitment, coordination, trust, communication, information sharing, flexibility, and dependence are major to meaningful relationships. However, organizations pay more attention to building better relationships with suppliers by considering all these factors to ensure benefits from such relationships (Nyaga et al., 2010). Additionally, Prajogo et al. (2021) propose that when firms perceive their suppliers' capabilities and their maximum strategic values, it is more possible that they will achieve their process, goals, and strategies in a better way, which, in turn, reflect on getting a sustainable supply chain network. According to the previous arguments, this research assumes that organizations and suppliers are similarly affected by environmental forces because they work in the same industry and, therefore, these influences and forces may lead to more cooperation, building relationships between them, creating more opportunities for cooperation, avoiding threats, and achieving common goals. Moreover, this strategic relationship and full cooperation are catalysts in achieving a sustainable strategy. Accordingly, the following hypothesis is proposed: 
$\mathbf{H}_{4}$ : Supplier relationships have a significant direct impact on Supply chain Sustainability.

H5: Supplier relationships mediate the relationship between environmental forces and Supply chain Sustainability.

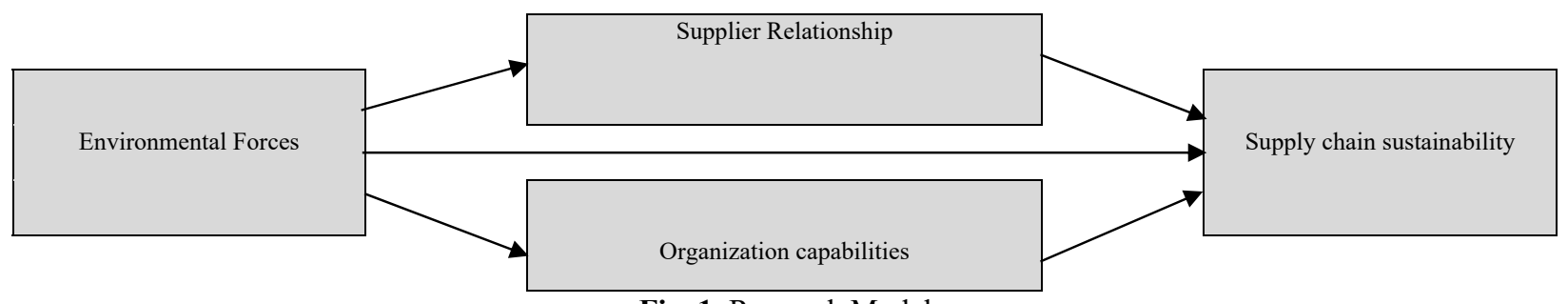

Fig. 1. Research Model

\section{Methods}

This research paper applied a survey in Jordanian food manufacturing companies. The strategy of research sampling was intended to achieve the representatives of research findings. In addition, the analysis unit of this research was a manufacturing company. The sample was obtained among food firms listed by the Jordan Chamber of industry. To select the sample, a convenient sampling approach was applied. The number of firms selected was limited to 63 firms. Different managers at different organizational levels were the main respondents in this research including operations, supply chain, and senior managers. Accordingly, the total number of questionnaires that were distributed was 520, while 410 questionnaires were analyzed with a response rate of $78.8 \%$. A five-point Likert scale through a structured questionnaire was applied where respondents judged different statements about independent, mediated, and dependent variables. Structural equation modeling by using SmartPLS 3 was conducted. Following (Sarstedt et al., 2016; Hair et al., 2013) recommendations, PLS-SEM considered a composite structure and mediation relationship.

\section{Results}

Scale validity and reliability were conducted to validate all research variables simultaneously. All measures and all fit indices indicate the good convergent validity of the constructs (Hair et al., 2017). The research constructs also indicated high reliability, as shown by the result of composite reliability, which exceeds 0.70 . According to (Hair et al., 2021), a CR of 0.60 to 0.70 is acceptable. The values of average variance extracted (AVE) were above 0.5, which supports the constructs' discriminant validity. Additionally, Cronbach's alpha values were also above 0.7 , which indicates a high-reliability level (Sekaran and Bougie, 2019). Table (1) summarizes these results.

Table 1

Scale validity and reliability

\begin{tabular}{lccc}
\hline Constructs & Alpha Cronbach's & Composite Reliability (CR) & AVE \\
\hline Environmental Forces & 0.882 & 0.907 & 0.551 \\
Organization Capabilities & 0.919 & 0.931 & 0.533 \\
Supplier Relationship & 0.785 & 0.866 & 0.624 \\
Supply chain Sustainability & 0.894 & 0.922 & 0.704 \\
\hline
\end{tabular}

Having confirmed the four variables, we made the compound values for variables. The result reveals that the kurtosis and skewness test values are within accepted ranges $(<7, \pm 1)$, respectively, which indicates no violation of normality. Furthermore, Pearson bivariate correlations were conducted among all constructs, and the results confirm no concerns for multicollinearity among the variables. Table 2 summarizes these results.

Table 2

The summary of correlation matrix

\begin{tabular}{lccc}
\hline Constructs & EF & OC & SR \\
\hline Environmental Forces (EF) & 0.742 & & \\
Organization Capabilities (OC) & 0.504 & 0.730 & \\
Supplier Relationship (SR) & 0.689 & 0.542 & 0.790 \\
Supply chain Sustainability (SCS) & 0.393 & 0.582 & 0.545 \\
\hline
\end{tabular}

Table 3

The summary of path analysis

\begin{tabular}{|c|c|c|c|c|c|}
\hline Independent Variables & Dependent variables & $\beta$ & S.E & $\mathrm{t}$ - value & $P$ value \\
\hline Environmental Forces & Organization Capabilities & 0.504 & 0.044 & 11.366 & 0.000 \\
\hline Environmental Forces & Supplier Relationship & 0.689 & 0.029 & 23.728 & 0.000 \\
\hline Environmental Forces & Supply chain Sustainability & 0.070 & 0.060 & 1.168 & 0.243 \\
\hline Organization Capabilities & Supply chain Sustainability & 0.419 & 0.049 & 8.585 & 0.000 \\
\hline Supplier Relationship & Supply chain Sustainability & 0.366 & 0.064 & 5.689 & 0.000 \\
\hline
\end{tabular}


Table 4

The results of indirect effect

\begin{tabular}{lccccc}
\hline Independent Variables & $\beta$ & S.E & $\mathrm{t}$ - value & Confidence Level & $\mathrm{P}$ \\
\hline Environmental Forces $\rightarrow$ Organization Capabilities $\rightarrow$ Supply chain Sustainability & 0.211 & 0.031 & 6.824 & $(0.150-0.272)$ & 0.000 \\
Environmental Forces $\rightarrow$ Supplier Relationship $\rightarrow$ Supply chain Sustainability & 0.252 & 0.049 & 5.168 & $(0.156-0.348)$ & 0.000 \\
\hline
\end{tabular}

\section{Discussion and conclusion}

A sustainable supply chain can be seen as all organization's processes implementing innovation, strategy, and agility with changes to achieve waste reduction, cooperative relationship, and social responsibility through embracing environmental issues and plans that are completely combined with the organization's goals (Haden et al., 2009). This paper investigated how and under what circumstances supply chain sustainability is affected by environmental forces, organizational capabilities, and supplier relationships from the employee perspective. The following paragraphs will discuss the main research findings.

Hypothesis 1 results obtained from analysis and shown in Table 3 reveal that environmental forces directly impact supply chain sustainability. As well, they pointed out a direct impact on both variables' organizational capabilities and supplier relationships. This result makes sense, as it has appeared increasingly significant and challenging for companies to adopt the changes, respond to the community, and sustain their agile supply chain agility performance (Saeed and Kersten, 2019). Prior empirical studies (Hsu et al., 2013; Varsei et al., 2014) figured out that the additional the company understands the surrounding environment and its various variables, the more it reflects on its capabilities, infrastructure, and resources, which contribute to building better relationships with supply chain partners, and ultimately, this results in a better sustainable supply chain network.

Furthermore, the result of hypothesis 2 shows the organizational capabilities' effect on supply chain sustainability. This means that the availability of different resources, equipment, experiences, cultures, strategies, and other capabilities within the organization not only increases organizational success but also intensifies the relationship between supply chain partners, avoiding any potential risk. However, this result confirms the prior scholars' results (Ahmed et al., 2020; Sanders \& Premus, 2005), who pointed out that the continuous development of internal and external firms' capabilities can contribute to the supply chain sustainability practices and comment about working according to high environmental standards.

Hypothesis 4 predicted that supplier relationships directly impact supply chain sustainability. The results confirm and support this hypothesis. This outcome confirms the Prajogo et al.'s (2021) results, who stated that as companies understand the significance of expanding their impact on their partner's resources and capabilities endowments, they similarly develop their assessments of partners elsewhere a mere basis of different materials and capabilities, mainly for the crucial supplier who provide inimitable and valuable capabilities. Regarding this result, we can conclude that as companies seek to achieve more entrenched logistics activities, they must focus and develop their capabilities as possible resources that would enhance their performance.

Hypotheses 3 and 5 predicted that organizational capabilities and supplier relationships have a mediation impact among environmental forces and sustainability. The results confirm and support these hypotheses. Previous literature did not examine this relationship empirically but proposed that there is an underlying direct relationship among these variables.

\section{Implication and limitation}

We argued throughout this paper that the enduring pressure on companies to implement and consider sustainable supply chain process successfully should be considered first of all full thoughtful and realize of not only the pressure and components of environmental forces to generate awareness but similarly on the relationship with a supplier and organizational capabilities. By doing this, this paper addressed the variables that must be cautiously measured and considered to maximize the success level for supply chain sustainability. The discussion and theoretical review showed through this study may open the door for conducting more further research. Besides, future research can assess the proposed models in different contexts.

Context. Practically, the findings hopefully support the top management in the Jordanian food manufacturer to consider sustainability matters that have become an essential requirement for society and customers. The practical results men and theoretical assessment of the Jordanian manufacture have controlled to the identification of specific strategic directions to enhance the supply chain sustainability concept. Finally, we acknowledge many limitations in this research include no difference has been made amongst the sample concerning their perceptions of the investigated research issues. Furthermore, the clarification of the results was grounded on a previous studies review and the researcher's point of view and insights of the debated concerns.

\section{References}

Afum, E., Issau, K., Agyabeng-Mensah, Y., Baah, C., Dacosta, E., Essandoh, E., \& Boateng, E. A. (2021). The missing links of sustainable supply chain management and green radical product innovation between sustainable entrepreneurship orientation and sustainability performance. Journal of Engineering, Design and Technology. 
Ahmed, W., Ashraf, M. S., Khan, S. A., Kusi-Sarpong, S., Arhin, F. K., Kusi-Sarpong, H., \& Najmi, A. (2020). Analyzing the impact of environmental collaboration among supply chain stakeholders on a firm's sustainable performance. Operations Management Research.

Alhawamdeh, H. M., \& Alsmairat, M. A. (2019). Strategic Decision Making and Organization Performance: A Literature Review. International Review of Management and Marketing, 9(4), 95.

Aljuraid, N., \& Alsmairat, M. (2021). The interplay between empowerment, minimum experience and performance: An empirical study on Saudi context. Management Science Letters, 11(2), 675-680.

Alzghoul, A. (2017). The Role of Leadership Style on Employee Outcome: An Overview. American Academic \& Scholarly Research Journal, 9(5).

Alzghoul, A., Elrehail, H., Emeagwali, O. L., \& AlShboul, M. K. (2018). Knowledge management, workplace climate, creativity and performance: The role of authentic leadership. Journal of Workplace Learning, 30(8), 592-612.

Ambrose, E., Marshall, D., \& Lynch, D. (2010). Buyer supplier perspectives on supply chain relationships. International Journal of Operations \& Production Management, 30(12), 1269-1290

Bae, H. S. (2017). The effect of environmental capabilities on environmental strategy and environmental performance of Korean exporters for green supply chain management. The Asian Journal of Shipping and Logistics, 33(3), $167-176$.

Berry, M. A., \& Rondinelli, D. A. (1998). Proactive corporate environmental management: A new industrial revolution. Academy of Management Perspectives, 12(2), 38-50.

Borland, H., Ambrosini, V., Lindgreen, A., \& Vanhamme, J. (2016). Building theory at the intersection of ecological sustainability and strategic management. Journal of Business Ethics, 135(2), 293-307.

Daugherty, P. J. (2011). Review of logistics and supply chain relationship literature and suggested research agenda. International Journal of Physical Distribution \& Logistics Management, 41(1), 16-31.

Dzhengiz, T., \& Niesten, E. (2020). Competences for environmental sustainability: A systematic review on the impact of absorptive capacity and capabilities. Journal of Business Ethics, 162(4), 881-906.

Ekins, P., \& Zenghelis, D. (2021). The costs and benefits of environmental sustainability. Sustainability Science, 16(3), 949965.

Elrehail, H., Emeagwali, O. L., Alsaad, A., \& Alzghoul, A. (2018). The impact of transformational and authentic leadership on innovation in higher education: The contingent role of knowledge sharing. Telematics and Informatics, 35(1), 55-67.

Emmett, S., \& Sood, V. (2010). Green supply chains: An action manifesto. John Wiley \& Sons.

Giantari, I. G. A. K., \& Sukaatmadja, I. P. G. (2021). Effects of environmental orientation, green marketing mix and social capital on the competitive advantage of real estate developers in Bali. Property Management.

Giunipero, L. C., Hooker, R. E., \& Denslow, D. (2012). Purchasing and supply management sustainability: Drivers and barriers. Journal of Purchasing and Supply Management, 18(4), 258-269.

Gong, M., You, Z., Wang, L., \& Cheng, J. (2020). Environmental regulation, trade comparative advantage, and the manufacturing industry's green transformation and upgrading. International Journal of Environmental Research and Public Health, 17(8), 2823.

Graham, S. (2020). The influence of external and internal stakeholder pressures on the implementation of upstream environmental supply chain practices. Business \& Society, 59(2), 351-383.

Haden, O. Humphreys.(2009). Historical, practical and theoretical perspective on green innovation. Management Decision, 47(7), 1041-1055.

Hair Jr, J. F., Hult, G. T. M., Ringle, C. M., \& Sarstedt, M. (2021). A primer on partial least squares structural equation modeling (PLS-SEM). Sage publications.

Hair, J. F., Ringle, C. M., \& Sarstedt, M. (2013). Partial least squares structural equation modeling: Rigorous applications, better results and higher acceptance. Long Range Planning, 46(1-2), 1-12.

Hair, J., Hollingsworth, C. L., Randolph, A. B., \& Chong, A. Y. L. (2017). An updated and expanded assessment of PLSSEM in information systems research. Industrial Management \& Data Systems, 117(3), 442-458.

Han, W., Huang, Y., \& Macbeth, D. (2018). Performance measurement of cross-culture supply chain partnership: a case study in the Chinese automotive industry. International Journal of Production Research, 56(7), 2437-2451.

Hervani, A. A., Helms, M. M., \& Sarkis, J. (2005). Performance measurement for green supply chain management. Benchmarking: An International Journal., 12(4), 330-353.

Hsu, C. C., Tan, K. C., Zailani, S. H. M., \& Jayaraman, V. (2013). Supply chain drivers that foster the development of green initiatives in an emerging economy. International Journal of Operations \& Production Management, 33(6), 656-688.

Huang, X., Tan, B. L., \& Ding, X. (2015). An exploratory survey of green supply chain management in Chinese manufacturing small and medium-sized enterprises: Pressures and drivers. Journal of Manufacturing Technology Management, 26(1), 80-103.

Kamau, I. N. (2013). Buyer-supplier relationships and organizational performance among large manufacturing firms in Nairobi, Kenya (Doctoral dissertation, University of Nairobi).

Karmaker, C. L., Ahmed, T., Ahmed, S., Ali, S. M., Moktadir, M. A., \& Kabir, G. (2021). Improving supply chain sustainability in the context of COVID-19 pandemic in an emerging economy: Exploring drivers using an integrated model. Sustainable Production and Consumption, 26, 411-427.

Kembi, L. (2021). Strategic relationships building with suppliers.

Khaddam, A. A., Alzghoul, A., Abusweilem, M. A., \& Abousweilem, F. (2021). Business intelligence and firm performance: a moderated-mediated model. The Service Industries Journal, 1-17. 
Kneipp, J. M., Gomes, C. M., Bichueti, R. S., Frizzo, K., \& Perlin, A. P. (2019). Sustainable innovation practices and their relationship with the performance of industrial companies. Revista de Gestão.

Köksal, D., Strähle, J., Müller, M., \& Freise, M. (2017). Social sustainable supply chain management in the textile and apparel industry-A literature review. Sustainability, 9(1), 100.

Lee, S. Y., \& Klassen, R. D. (2008). Drivers and enablers that foster environmental management capabilities in small-and medium-sized suppliers in supply chains. Production and Operations management, 17(6), 573-586

Menguc, B., Auh, S., \& Ozanne, L. (2010). The interactive effect of internal and external factors on a proactive environmental strategy and its influence on a firm's performance. Journal of Business Ethics, 94(2), 279-298.

Mert, İ. S., Sen, C., \& Alzghoul, A. (2021). Organizational justice, life satisfaction, and happiness: the mediating role of workplace social courage. Kybernetes.

Min, S., Roath, A. S., Daugherty, P. J., Genchev, S. E., Chen, H., Arndt, A. D., \& Richey, R. G. (2005). Supply chain collaboration: what's happening?. The international Journal of Logistics Management., 16(2), 237-256.

Moneva, J. M., \& Ortas, E. (2010). Corporate environmental and financial performance: a multivariate approach. Industrial Management \& Data Systems, 110(2).

Narasimhan, R., Talluri, S. and Mahapatra, S.K. (2006). Multiproduct, multicriteria model for supplier selection with product life-cycle considerations. Decision Sciences, 37(4), 577-603

Nyaga, G. N., Whipple, J. M., \& Lynch, D. F. (2010). Examining supply chain relationships: do buyer and supplier perspectives on collaborative relationships differ?. Journal of Operations Management, 28(2), 101-114.

Paillé, P., Chen, Y., Boiral, O., \& Jin, J. (2014). The impact of human resource management on environmental performance: An employee-level study. Journal of Business Ethics, 121(3), 451-466.

Plambeck, E. L. (2007). The greening of Wal-Mart's supply chain. Supply Chain Management Review, 11(5).

Prajogo, D., Mena, C., \& Chowdhury, M. (2021). The role of strategic collaborations and relational capital in enhancing product performance-a moderated-mediated model. International Journal of Operations \& Production Management, 41(3), 206-226.

Pulles, N. J., Schiele, H., Veldman, J., \& Hüttinger, L. (2016). The impact of customer attractiveness and supplier satisfaction on becoming a preferred customer. Industrial Marketing Management, 54, 129-140.

Rothenberg, S., Pil, F. K., \& Maxwell, J. (2001). Lean, green, and the quest for superior environmental performance. Production and Operations Management, 10(3), 228-243.

Russo, M. V., \& Harrison, N. S. (2005). Organizational design and environmental performance: Clues from the electronics industry. Academy of Management Journal, 48(4), 582-593.

Saeed, M. A., \& Kersten, W. (2019). Drivers of sustainable supply chain management: identification and classification. Sustainability, 11(4), 1137.

Saeed, M. A., Waseek, I., \& Kersten, W. (2017). Literature review of drivers of sustainable supply chain management. In Proceedings of the Hamburg International Conference of Logistics (HICL) (pp. 159-184). epubli.

Sambasivan, M., Siew-Phaik, L., Mohamed, Z. A., \& Leong, Y. C. (2011). Impact of interdependence between supply chain partners on strategic alliance outcomes: role of relational capital as a mediating construct. Management Decision, 49(4).

Sanders, N. R., \& Premus, R. (2005). Modelling the relationship between firm IT capability, collaboration, and performance. Journal of Business Logistics, 26(1), 1-23.

Sarkis, J., Gonzalez-Torre, P., \& Adenso-Diaz, B. (2010). Stakeholder pressure and the adoption of environmental practices: The mediating effect of training. Journal of Operations Management, 28(2), 163-176.

Sarstedt, M., Hair, J. F., Ringle, C. M., Thiele, K. O., \& Gudergan, S. P. (2016). Estimation issues with PLS and CBSEM: where the bias lies!. Journal of Business Research, 69(10), 3998-4010.

Schrettle, S., Hinz, A., Scherrer-Rathje, M., \& Friedli, T. (2014). Turning sustainability into action: Explaining firms' sustainability efforts and their impact on firm performance. International Journal of Production Economics, 147, 73-84.

Sekaran, U., \& Bougie, R. (2019). Research methods for business: A skill building approach. John Wiley \& Sons.

Shou, Y., Shan, S., Chen, A., Cheng, Y., \& Boer, H. (2020). Aspirations and environmental performance feedback: a behavioral perspective for green supply chain management. International Journal of Operations \& Production Management.

Stonebraker, P. W., \& Liao, J. (2006). Supply chain integration: exploring product and environmental contingencies. Supply Chain Management: An International Journal, 11(1), 34-43.

Varsei, M., Soosay, C., Fahimnia, B., \& Sarkis, J. (2014). Framing sustainability performance of supply chains with multidimensional indicators. Supply Chain Management: An International Journal., 19(3), 242-257.

Veliyath, R., \& Fitzgerald, E. (2000). Firm capabilities, business strategies, customer preferences, and hypercompetitive arenas: the sustainability of competitive advantages with implications for firm competitiveness. Competitiveness Review: An International Business Journal.

Wegdam, C. (2021). The Effect of Reputation on the Four Stages of Buyer-Supplier Relationships and the Extent to which Buyers and Suppliers Preserve their Reputation in B2B Relationships in the Food Industry (Master's thesis, University of Twente). 
(C) 2022 by the authors; licensee Growing Science, Canada. This is an open access article distributed under the terms and conditions of the Creative Commons Attribution (CCBY) license (http://creativecommons.org/licenses/by/4.0/). 